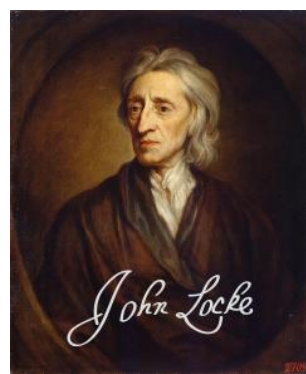

LOCKE STUDIES

Vol. 17

https://doi.org/10.5206/ls.2017.870 | ISSN: 2561-925X

Originally published: 2017

Published online: 01 JANUARY 2019

(c) Locke Studies, 2017

\title{
Locke's Ontology of Relations
}

\author{
SAMUEL C. RICKLESS (UNIVERSITY OF CALIFRONIA, SAN DIEGO)
}

Recommended citation:

Rickless, Samuel C. "Locke's Ontology of Relations." Locke Studies 17 (2017): 61-86.

https://doi.org/10.5206/ls.2017.870.

For more information about this article:

see this article's webpage.

Locke Studies is published by The John Locke Society.

This is an open access article published under the terms of the Creative Commons AttributionNonCommercial-ShareAlike 4.0 International license, which permits use, distribution and reproduction in any medium, provided the original work is properly cited and shared under the original license. 


\title{
LOCKE'S ONTOLOGY OF RELATIONS
}

\author{
SAMUEL C. RICKLESS
}

\section{§1. Introduction}

In his An Essay Concerning Human Understanding, Locke's primary aim is to provide an empiricist theory of ideas that can support interesting results about the nature of language and knowledge. Within this theory, Locke distinguishes between simple ideas and complex ideas (E II.ii.1: 119). ${ }^{1}$ Roughly, an idea is complex if it has other ideas as parts; otherwise, it is simple. ${ }^{2}$ For Locke, as is well known, all simple ideas derive from sensation (perception through sight, taste, smell, hearing, or touch) or reflection (a form of introspection directed at mental acts) (E II.i.2-4: 104-106). Aetiology also plays a role in Locke's classification of complex ideas: ideas of modes, ideas of substances, and ideas of relations. ${ }^{3}$ All complex ideas are formed

1 All references to Locke's Essay are to the P. H. Nidditch edition (1975). The standard abbreviation for each reference is 'E Book.Chapter.Section: Page Number'.

2 But see E II.xv.9: 201-3, and the accompanying footnote, for complications, which I discuss in Rickless 2014, 42-43.

${ }^{3}$ Officially, Locke claims that complex ideas 'may be all reduced' under 'three Heads': Modes, Substances, and Relations (E II.xii.3: 164). In keeping with this way of speaking, Locke says that 'Modes I call such complex Ideas, which...contain not in them the supposition of subsisting by themselves, but are considered as Dependences on, or Affections of Substances' (E II.xii.4: 165). Modes, then, it seems, are complex ideas, and this is exactly how Locke speaks of them elsewhere in the Essay (e.g., at E II.xxii.1-2: 288). One might then expect Locke to say that substances are complex ideas that contain in them the supposition of subsisting by themselves. But Locke frustrates this expectation when he calls the latter sort of complex ideas 'Ideas of Substances' (E II.xii.6: 165), and continues to speak of 'ideas of substances' throughout the Essay (E II.xxi.3: 234; E II.xxii.1: 288; E II.xxiii.3: 297; E II.xxiii.8: 300; and so on). So, it seems, Locke takes modes (and ideas of substances) to be ideas in minds, but takes substances (such as human beings, sheep, and apples) to exist outside of minds. And yet Locke doesn't keep to this nomenclature consistently. At first, he distinguishes between simple modes and mixed modes, characterizing the former as 'combinations of the same simple Idea, without the mixture of any other', and the latter as ideas 'compounded of simple Ideas of several kinds' (E II.xii.5: 165). But later he changes tack, writing in numerous places of 'ideas of modes' (or, when applicable, of 
by a voluntary act of combination or composition. ${ }^{4}$ Ideas of modes, such as numbers, beauty, and theft (E II.xii.5: 165) are formed without considering whether the combinations conform to real patterns existing in the world (E II.xi.6: 158, E II.xxii.1: 288, E II.xxxi.3: 376). Ideas of substances (such as human beings, sheep, and armies-E II.xii.6: 165), by contrast, are formed with a desire 'to copy Things, as they really do exist' (E II.xxxi.3: 377). Ideas of relations are like ideas of modes (E II.xxxi.14: 383-84), except that their aetiology includes, in addition to the mental act of composition, the distinct mental act of comparison on the basis of some respect or dimension (E II.xi.4: 157, E II.xxv.1: 319).

On top of this appeal to aetiology, however, Locke appears to call on metaphysics to categorize complex ideas. This is strongly suggested by Locke's nomenclature, ideas of substances being so-called because they represent substances, ideas of modes being so-called because they represent modes, and ideas of relations being so-called because they represent relations. The question is:

'ideas of simple modes' or 'ideas of mixed modes')—see, e.g., E II.xxviii.4: 351; E II.xxxi.3: 376; E II.xxxii.10-12: 387-88; E II.xxxii.17: 390. And sometimes he discusses modes as if they were entities other than ideas. For example, he writes that 'the greatest part of mixed Modes, being Actions, which perish at their Birth, are not capable of a lasting Duration, as Substances, which are the Actors' (E III.vi.42: 465), and that mental 'Actions' (E II.xix.1: 226) or 'Operations of the mind', such as recollection, contemplation, attention, and volition, are 'various Modes of thinking, which the Mind may observe in it self, and so have distinct Ideas of' (E II.xix.2: 227).

Regimentation of Locke's nomenclature is therefore required if we are not to read him as completely confused. More discussion of these issues would surely be helpful, but my own view is that Locke is best read as holding the view that modes, such as actions of body and mind, should be distinguished from ideas of modes, and that he uses the word 'mode' ambiguously to refer sometimes to the former and sometimes to the latter (see Rickless 2014, 48 ff.). In the interest of clarity, I will use 'modes' to refer to modes, and 'ideas of modes' to refer to ideas of modes. In order not to beg any questions, I will do the same for relations, using 'relations' to refer to relations, and 'ideas of relations' to refer to ideas of relations.

${ }^{4}$ For Locke's claim that complex ideas are made by combination/composition, see, e.g., E II.xi.6: 158 and E II.xii.2: 164). For his claim that complex ideas are made voluntarily, see E II.xii.2: 164 (heading) and E II.xxx.3: 373 (heading and main text), as well as E II.xxxi.3: 376, where Locke writes of '[o]ur complex Ideas of Modes, being voluntary Collections of simple Ideas'. 
what, according to Locke, is the ontological status of these entities?

There is widespread scholarly agreement that Locke takes substances to be real things existing in a world outside our minds. But for many years there has been disagreement about whether the furniture in Locke's universe includes modes and relations. Some hold that modes/relations exist mind-independently, others that modes/relations exist but only mind-dependently, and yet others that modes/relations do not exist. And things are even more complicated than this, for at least one scholar, Stuart (2013), thinks that what is true of modes does not automatically apply to relations: whereas modes exist, relations do not.

In this paper, I focus attention on the category of relations, leaving aside the category of modes except where reference to it is needed. My main thesis is that Locke gives us every reason to believe that he takes relations to exist mind-independently, and no reason to believe otherwise. ${ }^{5}$ The position I defend may strike the reader as commonsensical. But it has come under sustained criticism by prominent and very able Locke scholars in recent years, criticism that shows no signs of abating. So I think it is time for us to consider what may be said in defense of it.

\section{\$2. The Interpretive Landscape}

In Book II, Chapter 12 of the Essay, Locke tells us something about the ontology of substances and modes. Substances are 'distinct particular things subsisting by themselves' (E II.xii.6: 165), and modes are 'Dependences on, or Affections of Substances' (E II.xii.4: 165). By contrast, he is curiously unforthcoming when it comes to the ontology of relations in the same chapter, telling us only that 'The last sort of complex Ideas, is that we call Relation, which consists in the consideration and comparing one Idea with another' (E II.xii.7: 166). This is a statement about ideas of relation, rather than a statement about

${ }^{5}$ For the record, my view is that Locke takes modes to be no less real than substances and relations. Some of my reasons for this are similar to the reasons provided by Stuart 2013, 19-23. 
relations per se. What, then, does Locke take the ontological status of relations to be?

Consider two children of the same parents. According to antirealism, there is no such thing in the universe as the sibling relation. Perhaps there are substances (the two children and the parents) and there are actions that result in procreation (modes), and it may be true to say that the two children are siblings. But on the anti-realist picture, the proposition that the children are siblings is not made true by the existence of a sibling relation between them. This is because there is no such relation. So either it is false that the children are siblings, or something other than a relation between them is what makes it true that they are siblings. As an interpretation of Locke, anti-realism about relations has been defended by Matthew Stuart (2013). ${ }^{6}$

Opposed to anti-realism is the thesis of realism about relations. According to realism, there are such things as relations in the world: they are not merely fictional or chimerical entities. The question for realists is whether, and, if so, how relations are dependent for their existence on the existence of minds. According to conceptualism, relations are mental acts, or depend for their existence on the existence of such acts. It can be difficult sometimes to distinguish between anti-realists and conceptualists, because both of them sometimes characterize their own positions by saying that relations aren't real. For antirealists, this means that relations don't exist. But for conceptualists, this means that relations don't exist independently of mental activities. Conceptualist interpretations of Locke have been put forward by T. H. Green (1885), James Gibson (1917), David L. Perry (1967) and, more recently, Walter Ott (2009; forthcoming). ${ }^{7}$

${ }^{6}$ For example, Stuart $(2013,30)$ writes: '[Locke's] view is that there are ideas of relations, but no relations'.

${ }^{7}$ Gibson 1917, 193-95, who says that Locke claims, but does not consistently hold to the position, that relations are not real, also assimilates Locke's position to Leibniz's, according to which relations are 'entia mentalia dependent upon the activity of a comparing mind' (1917, 292). In saying that Locke holds that relations are not real, then, Gibson supposes that reality is not the same as existence, but rather a matter of 
We can think of realists who are opposed to conceptualism as non-conceptualist realists. According to this view, relations, like substances, are not dependent for their existence on mental acts. As an interpretation of Locke, this view has been defended (briefly) by Odegard (1969), and it is the interpretation of Locke that I defend here. ${ }^{8}$

mind-independent existence. (Thanks to Matthew Stuart for pointing me to the second Gibson reference.)

${ }^{8}$ Non-conceptualist realists include Bennett (1971) and Langton (2000). These two authors have debated a separate question: whether Locke is a reductionist or an antireductionist. Reductionists accept, while anti-reductionists deny, that relations are reducible to (or supervenient on) mind-independent non-relational (intrinsic) properties of substances. Bennett (1971) briefly offers reductionism as an interpretation of Locke, while Odegard (1969) and Langton (2000) argue that the same passage Bennett reads as evidence of reductionism is actually evidence of anti-reductionism. This is an important debate within the non-conceptualist realist camp, but it is moot if anti-realism or conceptualism is the right interpretation of Locke's ontology of relations. My main focus in this paper is on the debate among proponents of the anti-realist, conceptualist, and realist interpretations.

Pasnau $(2011,528)$ claims that Locke is not a 'realist' about relations. By this Pasnau means that Locke's relations do not introduce any ontological commitment beyond bodies in motion $(2011,520)$. According to Pasnau, then, using the nomenclature of this paper Locke counts as a (realist) reductionist. However, it should be noted that the one passage that Pasnau cites as evidence of Locke's reductionism (that relations have 'no other reality but what they have in the minds of men'- $\mathrm{E}$ II.xxx.4: 373) suggests conceptualism rather than reductionism. I discuss this passage in greater detail below.

Ott $(2009,159)$ writes that, for Locke, 'relations...are reducible to the nonrelational qualities of their relata'. This suggests that Ott takes a (realist) reductionist line, similar to Pasnau's. But later in the same chapter, Ott (2009, 168 and 167) claims that 'the best overall account of Locke's view' is that 'while relations are fully minddependent and have no real being, it remains the case that the mind-independent world provides a foundation (and a justification) for us to form the ideas of relations that we do'. Ott calls this position 'foundational conceptualism', and, according to this paper's taxonomy, it is clearly a version of conceptualism, rather than a version of reductionism.

Bolton (2007, 92) is more non-committal. On her view, passages that suggest conceptualism 'by no means settle the question whether all relations are minddependent, for Locke'. She continues: 'Rather than addressing the metaphysical issue, the discussion is intended to bring out how we think of relations - how they are presented in thought'. As I argue below, although I agree with Bolton that much of Locke's discussion of relations focuses on how we think of relations and that Locke does little to address the metaphysical status of relations, it is possible to extract some metaphysical commitments from Locke's texts. 
The structure of the paper reflects the landscape just described. After critical discussion of the anti-realist interpretation (section 3 ) and the conceptualist interpretation (section 4), I move on to defend the non-conceptualist realist interpretation (section 5).

\section{§3. Against the Anti-Realist Interpretation}

The main argument in favor of interpreting Locke as an antirealist about relations relies on a passage culled from the chapter of the Essay titled 'Of Relation':

Secondly, This farther may be considered concerning Relation, That though it be not contained in the real existence of Things, but something extraneous, and superinduced: yet the Ideas which relative Words stand for, are often clearer, and more distinct, than of those Substances to which they do belong. (E II.xxv.8: 322)

As Stuart (2013) rightly argues, in order to understand this passage we need to understand what Locke means by 'contained in the real existence of Things' and by 'extraneous, and superinduced'. Stuart adduces a great deal of textual evidence to support the view that the first phrase should be understood in a 'most ordinary, straightforward sense'. In this sense, what is contained in the real existence of things is 'what exists, or what exists independently of us' $(2013,27)$. For example, Locke tells us that ideas of certain kinds of modes 'were never offered to [the] Mind by the real existence of things', by which he means that it is possible to acquire the ideas of such modes as sacrilege or murder 'without ever seeing either of them committed' (E II.xxii.3: 289). And it is reasonable to understand Locke to be saying here that it is possible to acquire the ideas of sacrilege and murder merely by 'enumerating...the simple Ideas which these words [i.e., 'sacrilege' and 'murder'] stand for, without perceiving anything that exists (or anything that exists mindindependently) — see also E II.xxxii.13: 388.

As for the second phrase ('extraneous, and superinduced'), Stuart points out that 'extraneous' makes only two other appearances in the Essay. At E II.xxxii.4: 385, Locke writes: 
'When-ever the Mind refers any of its Ideas to any thing extraneous to them, they are then capable to be called true or false'. And at E IV.xv.3: 655, he writes: 'That which makes me believe, is something extraneous to the thing I believe.' In both cases, as Stuart also rightly notes, what it is for $\mathrm{X}$ to be extraneous to $\mathrm{Y}$ is for $\mathrm{X}$ to be other than, i.e., distinct from, $\mathrm{Y}$ (2013, 31, n. 39): ideas are capable of being called 'true' or 'false' when the mind refers them to something that is distinct from them, and what makes me believe a proposition is something (i.e., some evidence) distinct from the proposition believed. As for the word 'superinduced', Stuart notes (again, rightly) that it appears in only one other passage in the Essay, a passage in which Locke speaks of 'the notion of a Father; which is a notion superinduced to the Substance, or Man, and refers only to an act of that thing called Man' (E II.xxv.4: 320). According to Stuart, 'superinduced' should here be understood to mean 'added', in the sense of 'projected on to the world', rather than being copied from it $(2013,31)$.

Putting all this careful research together, Stuart concludes that when Locke says that relation is "not contained in the real existence of Things, but something extraneous, and superinduced', he means (i) that relation is not contained in the (mindindependent) world, (ii) that it is distinct from the (mindindependent) world, and (iii) that our ideas of relation are merely projected onto, rather than being copied from, the (mindindependent) world.

I fully grant that Stuart's interpretation makes good sense of the first part of the E II.xxv.8 passage. It certainly appears that Locke is saying that relations are not contained in the (mindindependent) world, that they are not part of the furniture of the universe, when he says that they are 'not contained in the real existence of Things'. But Stuart's interpretation really doesn't make good sense of the second part of the passage. If Locke is read as talking about relations (which is how Stuart reads the first part of the passage), and the word 'superinduced' means 'added', then Locke's claim that relations are superinduced should be understood to mean that relations are added to the (mind- 
independent) world, not that ideas of relations are projected onto it. But if relations are added to the world, then we may safely presume that they exist, on the reasonable assumption that $\mathrm{X}$ cannot be added to $\mathrm{Y}$ if $\mathrm{Y}$ exists but $\mathrm{X}$ does not. ${ }^{9}$

But if the E II.xxv.8 passage doesn't mean what Stuart thinks it means, then what does it mean? The first clue comes from a more careful reading of the other passage in which Locke uses the word 'superinduced': 'Those who have far different Ideas of a Man, may yet agree in the notion of a Father: which is a notion superinduced to the Substance, or Man, and refers only to an act of that thing called Man' (E II.xxv.4: 320). Notice that what is said here to be superinduced to a substance is not the father relation, but the notion of a father. It is clear from many sources that 'notion' here is being used interchangeably with 'idea'. First, there is the local context. Locke is telling us that those who have different ideas of a man may yet have the same notion of a father. But this is an illustration of a more general claim, a claim that immediately precedes the passage just quoted: 'This farther may be observed, That the Ideas of Relation, may be the same in Men, who have far different Ideas of the Things that are related, or that are thus compared' (E II.xxv.4: 320). In other words, those who have different ideas of related substances may yet have the same idea of their relation. The notion of a father, then, is here functioning as an instance of the general idea of a relation.

Second, at the beginning of the Essay Locke himself tells us that he uses the term 'idea' 'to express whatever is meant by Phantasm, Notion, Species, or whatever it is, which the Mind can be employ'd about in thinking' (E I.i.8: 47). So Locke explicitly announces that he will use the word 'idea' to mean the same as

${ }^{9}$ It might be objected that it is possible for a novelist to 'add' a fictional character to the world. A complete reply to this objection would require extensive discussion of the ontology of fiction, which would take us beyond the scope of this essay. In brief, I grant that it is possible for novelists to add fictional characters to the world, but I insist that fictional characters exist, that they are existent abstracta, and that the fact that these characters are created does not detract from their existence (any more than the fact that a song or painting is created doesn't take away from its existence). For a defence of the sort of view I embrace, see Kripke 2013, 69-74. 
the word 'notion'. Third, Locke himself plainly uses the word 'notion' in this way in many other places in the Essay. Here are just a few examples. He writes that sensation and reflection are 'the Groundwork, whereon to build all those Notions, which ever [one] shall have naturally in this World' (E II.i.24: 118), where this is clearly an instance of his oft-repeated claim that sensation and reflection are the ultimate sources of all our ideas. And he suggests that it is absurd to suppose that 'a blind Man hath Ideas of Colours, and a deaf Man true distinct Notions of Sounds' (E II.ii.2: 120), where it is clear that 'Notions of Sounds' is here being used to mean the same as 'Ideas of Sounds' (see also E II.xiv.4: 182).

The textual evidence is therefore overwhelming that when Locke tells us, at E II.xxv.4, that the notion of a father is superinduced to the man, he means that the idea of a father is superinduced to the man. Given that Locke uses 'superinduced' in both this passage and at E II.xxv.8 and that the passages are only a few sections apart, the most reasonable hypothesis is that when Locke says in the latter passage that 'Relation [is] superinduced' he means that the idea of relation is superinduced, not that relation itself (i.e., what the word 'relation' and the idea of relation refer to, if anything) is superinduced.

It should be noted that Locke often uses words for things to refer to ideas of those things. Stuart himself recognizes that Locke fails 'to always carefully distinguish ideas and their objects'. In particular, as Stuart emphasizes, '[v]ery often one can read apparent references to modes as careless talk about ideas of modes' $(2013,18)$. For example, Locke tells us that there are three ways to 'get the Ideas of mixed Modes', the first two of which are ' 1 . By Experience and Observation of things themselves. Thus by seeing two Men wrestle, or fence, we get the Idea of wrestling or fencing. 2. By Invention, or voluntary putting together of several simple Ideas in our own Minds: So he that first invented Printing, or Etching, had an Idea of it in his Mind, before it ever existed' (E II.xxii.9: 291-92). Here it is plain that the mixed modes are the activities of wrestling, fencing, printing, and etching, and that we acquire ideas of these activities 
either by observation or by the mental act of combining simpler ideas. One would then expect Locke to say that a lie is a mixed mode, as distinguished from the idea of a lie, which is an idea of a mixed mode. But what Locke says in the very same section is this: 'Thus the mixed Mode, which the word Lye stands for, is made of...simple Ideas'. This is in keeping with Locke's unfortunate definition of modes as complex ideas (E II.xii.4: 165), where simple modes are 'variations, or different combinations of the same simple Idea' and mixed modes are 'compounded of simple Ideas of several kinds' (E II.xii.5: 165). ${ }^{10}$

The text of E II.xxv.8 should therefore be read as making the following point: 'Though ideas of relations are not contained in the real existence of things, but are something extraneous and superinduced, these ideas are often clearer and more distinct than the ideas of those substances to which the relations belong'. ${ }^{11}$

${ }^{10}$ See note 3 above for more on the distinction between modes and ideas of modes.

${ }^{11}$ Odegard $(1969,149)$ reads E II.xxv.8 differently. On his view, Locke is telling us that relations (such as fatherhood) are not intrinsic properties of substances. $\mathrm{He}$ suggests that Locke's 'contrast between 'what really exists in things' and 'what does not really exist in things' is... a contrast...between what exists in things regardless of other things and what exists in something only in virtue of other things'. His evidence for this is Locke's statement that, 'when I give Cajus the name Husband, I intimate some other Person...my Thought is led to something beyond Cajus, and there are two things brought into consideration' (E II.xxv.1: 319).

There are two problems with this suggestion. First, the evidence Odegard adduces for it (from E II.xxv.1) is not a fact about what exists or does not exist in things, but rather a fact about our ideas of those things. Locke is not telling us that Cajus's being a husband exists in him only in virtue of other things (namely, his spouse). Rather, Locke is saying that, in naming Cajus 'husband', one's mind is led to think of his spouse in such a way as to compare the idea of Cajus with the idea of his spouse. Second, one of the paradigms of relation for Locke is identity (E II.xxvii.1: 328). So if, as Odegard suggests, Locke's statement that relation does not really exist in things means that relations exist in things only in virtue of other things, it would follow that identity exists in things only in virtue of other things. But, according to Locke, this is clearly false: it is not in virtue of other things that Cajus is identical with Cajus.

Odegard $(1969,152)$ recognizes the existence of the latter problem, but does not address it successfully. He offers the following revised account of what Locke means in saying that relations do not really exist in things, namely, that 'relations are conceived by considering how things stand with respect to other things or to themselves'. But this account is not a statement about relations per se, but a statement about how we conceive of relations. At best, then, Odegard's revised account simply collapses into Locke's claim that ideas of relations are formed by the mental operation 
Note that there is nothing strange about the claim made in the first part of this sentence. The reason that ideas of relations are not contained in the real existence of things is that they do not exist in a world outside our minds; rather, these ideas exist in our minds. These ideas (not the relations themselves) are extraneous to the world outside our minds precisely because they are not contained in it, and they are superinduced to substances in that world, not by virtue of being literally added to those substances (what could that possibly mean?), but by virtue of existing over and above (i.e., separately from) the ideas of those substances. (Here again, we should read Locke's talk of $X$ as a means of referring to ideas of $X$.) Locke's point, in the case of fatherhood, for example, is that the idea of being a father, which is the idea of an act whereby one contributes to the generation of something of one's own kind, exists separately from the idea of a particular man. For when I think of a particular man as a positive being, what I put into my idea of him is nothing but ideas of his intrinsic properties: 'I have nothing in my Mind, but the complex Idea of the Species, Man'. But when I think of a particular man as a father, 'my Thought is led to something beyond' him, to an idea that is not already contained in my idea of him (E II.xxv.1: 319).

To this interpretation, it might be objected that the claim that ideas of relations do not exist in a world outside our minds (which is what I understand Locke to be claiming when he says that relations are not contained in the real existence of things) is trivially true of every idea whatsoever, not just ideas of relations. It might be concluded that on my interpretation, Locke's claim, though innocuous, is too innocuous to be plausible. ${ }^{12}$ In response, let me begin by agreeing that on my interpretation the first part of the relevant sentence at E II.xxv.8 expresses a trivial proposition, a proposition that is obviously true on its face, given that ideas exist only in minds. But I fail to see why this should

of comparing ideas (perhaps ideas of the same thing) in some respect or other. But this account tells us nothing about the ontological status of relations.

12 Thanks to Walter Ott for pressing this objection. 
detract from its plausibility. Trivial truths are not only obviously true, they are also obviously plausible precisely because they are obviously true. Perhaps the objection could be put differently, as the charge that it is implausible to suppose that Locke would be using a seemingly brash claim to state a trivial truth. But the claim is only seemingly brash to one who reads it as Ott and Stuart do, as stating something non-trivial. Moreover, the claim is made in passing, and is left aside as soon as stated, in order to focus on the main point of the section, which is that ideas of relations are often clearer and more distinct than the ideas of the substances that are held to be related. This is, I submit, exactly what one should expect of trivial claims.

Besides, Locke is hardly above stating trivial truths. For example, he tells us in the chapter on identity that 'tis evident, that, considered in any instant of its Existence, [an atom] is, in that instant, the same with it self'. Locke then seemingly argues for this triviality: 'For being, at that instant, what it is, and nothing else, it is the same, and so must continue, as long as its Existence is continued: for so long it will be the same, and no other' (E II.xxvii.3: 330). This is in keeping with Locke's general theory of demonstration, according to which knowledge obtained by proofs begins with the perception of self-evident propositions (such as 'white is not black', 'a circle is not a triangle', and 'three are more than two') (E IV.ii.1-2: 530-32). So I fail to see why the fact that an interpretation takes Locke to be making a trivial claim in passing detracts from its plausibility.

The case for reading Locke as an anti-realist about relations rests, it seems, on a single passage from E II.xxv.8, a passage that, as we have seen, is best read as making a claim about ideas of relations rather than a claim about relations themselves. I conclude that there is really no good textual reason to believe that Locke's position on relations is that they do not exist.

\section{\$4. Against the Conceptualist Interpretation}

If Locke is not an anti-realist about relations, then he is a realist about them. But realists about relations divide into conceptualists and non-conceptualists. According to conceptualism, relations 
depend for their existence on the existence of mental acts. Although Walter Ott is not the first to read Locke as a conceptualist, his arguments for this interpretation are the most extensive and the most sophisticated on offer. In what follows, I explain why Ott's arguments fail and why we should reject conceptualism as the best reading of Locke on relations.

Ott begins with the text that Stuart takes as his primary evidence for an anti-realist interpretation: 'Relation [is] not contained in the real existence of Things, but something extraneous, and superinduced' (E II.xxv.8: 322). As Ott sees it, '[o]n its face, this says that relations are not real elements of the extra-mental world but instead are creatures of the mind' (2009, 160). The first thing to notice is that there is nothing on the 'face' of the text to suggest such a reading. Locke does not use the word 'extra-mental', nor does he use any word or phrase synonymous with it, and he certainly does not say here that relations are creatures of the mind. But it is true that if superinducing relations is something the mind does, and 'superinduced' is interpreted to mean 'created', then Locke's claim that relations are superinduced can be read as the claim that relations are creatures of the mind. On this view, it would then make sense to read 'real' as 'extra-mental', and the first clause of the sentence could indeed be read as the claim that relations do not exist outside the mind. As we have seen, however, there is a great deal of evidence to support the view that Locke uses 'relation' in this passage to refer to 'ideas of relation' rather than to relations themselves; and the fact that ideas of relation do not exist outside the mind does not entail or suggest that relations themselves do not exist outside the mind (any more than the fact that ideas of substances are mind-dependent entails or suggests that substances themselves are mind-dependent). Moreover, even if superinducing is something the mind does, there is nothing in this context, or anywhere else in Locke's Works (as far as I am aware), or in records of seventeenth century English usage, to suggest that 'superinducing' is synonymous with "creating".

But this is only the first of several textual arguments Ott uses to support the conceptualist interpretation. First, there are 
passages (call them the 'comparison passages') in which Locke appears to identify relations with mental acts. I have only been able to find five in all:

The last sort of complex Ideas, is that we call Relation, which consists in the consideration and comparing one Idea with another (E II.xii.7: 166)

The nature therefore of Relation, consists in the referring, or comparing two things, one to another (E II.xxv.5: 321)

Relation is a way of comparing, or considering two things together (E II.xxv.7: 322)

Relation [is] the considering of one thing with another, which is extrinsical to it (E II.xxv.10: 323)

Relation [is] but my way of considering, or comparing two Things together (E III.x.33: 507)

In addition, there are passages in which Locke appears to tell us that relations are mind-dependent:

Mixed Modes and Relations, [have] no other reality, but what they have in the Minds of Men (E II.xxx.4: 373)

But mixed Modes and Relations, being Archetypes without Patterns, and so having nothing to represent but themselves, cannot but be adequate, every thing being so to it self (E II.xxxi.3: 377)

On the basis of these passages, Ott claims that conceptualism, 'on its face, is the official position of the Essay' (2009, 164).

Let me begin with the 'comparison' passages. The first thing to notice about these passages is that Locke's language is not uniform. In some places he appears to tell us that relations are or consist in referring/comparing/considering. But in other places, he appears to tell us that relations are or consist in ways of comparing/considering. In some places, he tells us that what are being considered/compared are things. In other places, he tells us that the objects of consideration/comparison are ideas. Assuming 
that Locke is not confused (and I don't think he is), the best explanation for these differences is inattention to detail or precision. Locke is obviously not being careful here. And this means that we ourselves need to be careful about treating what he says with the kind of literalness that he could not have intended.

Given Locke's inconsistent use of language, we are best served by looking at those aspects of his theory of ideas that are fixed points in the interpretation of his views on relation. As we have seen, Locke's ideas are either simple or complex, and complex ideas are of three sorts: modes, substances, and relations. Sometimes, Locke uses 'modes' to refer to 'ideas of modes', and uses 'relations' to refer to 'ideas of relations'.13 Indeed, he sometimes even uses 'substances' to refer to 'ideas of substances' (e.g., at E III.vi.21: 450, where he refers to substances, not ideas of substances, as made up of several distinct simple ideas). All complex ideas are produced by combining simple ideas, where combining (or, as Locke also calls it, 'composing') is a mental operation (E II.xi.6: 158). But, in addition, ideas of relation are produced (at least in part) by ('gotten from': E II.xxv.1: 319), and depend on (E II.xi.4: 157) the additional mental operation of comparing. This sets them apart from ideas of substances and ideas of modes.

And what exactly is the mental operation of comparing? Locke tells us that when the mind compares, it 'brings two things together, and, as it were, takes a view of them at once, though still considered as distinct'; it 'so considers one thing, that it does, as it were, bring it to, and set it by another, and carry its view from one to t'other' (E II.xxv.1: 319). Because comparing is a mental operation, the two things that are brought together in comparison are clearly ideas: 'The COMPARING them one with another...is another operation of the Mind about its Ideas' (E II.xi.4: 157see also E II.xii.1: 163 and E II.xxviii.18: 360). So comparison involves considering (or perceiving) two ideas together rather than separately, without blending or combining them. But Locke

${ }^{13}$ Again, see note 3 above. 
also tells us that the consideration of two (or more) ideas involved in comparing them must be in respect of some feature, such as 'Extent, Degrees, Time, Place, or any other Circumstances' (E II.xi.4: 157), which serves as the 'ground or occasion for their comparison' (E II.xxv.6: 321). For example, if I consider the idea of myself and the idea of my mother in one mental act, taking notice of both ideas at once, in respect of age, I will acquire the idea of my being younger than my mother. But if I consider the same ideas in respect of height, I will acquire the idea of my being taller than my mother. It is reasonable to presume that the resulting complex idea of my relative youth is composed of the idea of myself, the idea of my mother, and the idea of the occasion of comparison, namely age, while the complex idea of my relative height is composed of the idea of myself, the idea of my mother, and the idea of height. ${ }^{14}$

Let us now go back to the first of the 'comparison' passages:

The last sort of complex Ideas, is that we call Relation, which consists in the consideration and comparing one Idea with another (E II.xii.7: 166)

The first thing to notice about this passage is that it just doesn't make sense, if read literally. The passage tells us that some ideas consist in the consideration and comparing one idea with another. But in Locke's mental economy ideas are one thing and mental acts are quite another. More particularly, mental acts such as combination and comparison, which are 'about' ideas, are not themselves ideas. Second, it should be noted that 'Relation', in this context, must be understood to refer to ideas of relation. For Locke says that what we call 'relation' are complex ideas. But if relations are mental acts (as Ott believes), then it makes no sense to say that they are ideas.

The question now becomes: How should we interpret passages

\footnotetext{
14 The idea of a friend, which is an idea of relation, is composed of several ideas: the idea of man (twice over), the idea of love, the idea of readiness, the idea of action, and the idea of good. For a friend is 'a Man, who loves, and is ready to do good to another' (E II.xxviii.18: 360-61).
} 
that either make no sense or state something that we know the author takes to be false? My answer is that we should make the best sense of them that we can, given the fixed points in any interpretation of the author's worldview. What, then, could Locke possibly be using the first "comparison" passage to convey? The most straightforward answer, I submit, is this:

The last sort of complex ideas, namely ideas of relation, result from the comparing of one idea with another.

Notice, though, that there is nothing in this interpretation to suggest that Locke is trying to make a point about the ontology of relations themselves. What Locke is almost surely trying to say is better put as a claim with which we already know he agrees, namely that ideas of relation are complex ideas produced (in part) by the mental operation of comparison.

That this is the best reading of the first 'comparison' passage is confirmed when we take into account the local context of the last 'comparison' passage. Locke does say there that 'Relation [is] but my way of considering, or comparing two Things together', but this quotation is taken out of context. Here is the entire passage from which this sentence has been culled:

But in Modes and Relations, I cannot have Ideas disagreeing to the Existence of Things: for Modes being complex Ideas, made by the Mind at pleasure; and Relation being but my way of considering, or comparing two Things together, and so also an Idea of my own making, these Ideas can scarce be found to disagree with any Thing existing; since they are not in the Mind, as the Copies of Things regularly made by Nature, nor as Properties inseparably flowing from the internal Constitution or Essence of any Substance; but, as it were, Patterns lodg'd in my Memory, with names annexed to them, to denominate Actions and Relations by, as they come to exist (E III.x.33: 507)

In this passage, Locke says that both modes and relations are complex ideas made by the mind without any intention of thereby copying or representing some external substance or any of its properties. It is plain (by his reference to complex ideas) that he 
means to use 'modes' to refer to ideas of modes and 'relation' to refer to any idea of relation. So when he says that relation is his way of considering or comparing two things, he should be understood to mean that any idea of relation is a way of considering or comparing two things. But now we find ourselves facing a difficulty that is similar to the difficulty we faced when trying to interpret the first 'comparison' passage: ideas are not mental operations, nor are they ways of performing these operations. Given that the passage, properly parsed, states something Locke would never accept, we have no choice but to read it as stating something that makes sense given the rest of Locke's philosophical commitments, namely that ideas of relation stem from ways of considering and comparing two ideas, where a way of comparing two ideas is specified by the respect in which they are considered together. And this, I submit, is also how we should read the other three 'comparison' passages that appear in quick succession in E II.XXv.

Let us now consider the other two passages that might be read to suggest that relations (and modes) are mind-dependent. The first we might call the 'reality' passage:

Mixed Modes and Relations, [have] no other reality, but what they have in the Minds of Men (E II.xxx.4: 373)

As Stuart $(2013,21)$ notices, this passage is really about ideas of mixed modes and relations, rather than about the mixed modes and relations represented by those ideas. Stuart points out that this is revealed by the context in which the sentence appears: 'Secondly, Mixed Modes and Relations, having no other reality, but what they have in the Minds of Men, there is nothing more required to those kind of Ideas, to make them real, but that they be so framed, that there be a possibility of existing conformable to them' (E II.xxx.4: 373). The 'kind of ideas' to the reality of which Locke is referring are what he calls 'mixed modes' and 'relations'. But as we have already seen, Locke often uses these words to refer to ideas, rather than to what those ideas represent. This is a case in point. 
So what Locke is saying in the 'reality' passage is that ideas of mixed modes and relations have no other reality but what they have in the minds of men. The reason for this, as he tells us a few lines later, is that ideas of mixed modes and relations are their own archetypes (E II.xxx.4: 373), and hence cannot fail to be real inasmuch as they conform to themselves (and hence must conform to their archetypes). The reality of ideas of mixed modes and relations is therefore an intra-mental matter: such ideas are real, not because they conform to something that exists outside our minds, but because they conform to something that exists in our minds (namely, themselves). Within Locke's mental economy, this claim is both true and unsurprising. Locke is not here trying to put forward a controversial thesis about the ontological status of relations.

The second passage (which we might call the 'adequacy' passage) suggests that relations (as well as mixed modes) are ideas that represent themselves, rather than ideas that represent things in the world:

But mixed Modes and Relations, being Archetypes without Patterns, and so having nothing to represent but themselves, cannot but be adequate, every thing being so to it self (E II.xxxi.3: 377)

But here again Locke is using 'mixed Modes' and 'Relations' to refer to ideas of mixed modes and relations, rather than to mixed modes and relations themselves. What he is saying is that ideas of mixed modes and relations, being archetypes that represent themselves, are adequate. This is confirmed by Locke's restatement of the same point later in the same chapter: 'Thirdly, Complex Ideas of Modes and Relations, are Originals, and Archetypes; are not Copies, nor made after the Pattern of any real Existence, to which the Mind intends them to be conformable, and exactly to answer' (E II.xxxi.14: 383-84).

\section{\$5. For the Non-Conceptualist Realist Interpretation}

We have seen that the textual evidence for reading Locke as an anti-realist about relations is very thin. We have also seen that 
there is no good evidence for the claim that Locke takes relations to be mental acts. But is there any textual evidence for the interpretation that Locke's relations exist independently of mental acts?

Consider, first, that it would be odd for Locke to say, as he does at E II.xxv.5, that relations cease to exist when their relata cease to exist if he thought that relations were non-existent or existed in the mind. Locke says that if the relevant relata 'be removed, or cease to be, the Relation ceases', and illustrates this with the case of Cajus, who 'ceases to be [a father], only by the death of his son' (E II.xxv.5: 321-see also E II.xxviii.2: 349, where Locke says that natural relations in particular are 'as lasting as the Subjects to which they belong'). If the relation of father to son were non-existent, then it would make no sense to say that the relation 'ceases' when the son dies. And if the relation of father to son were a mental act, then there would be no reason to think that it would cease to be if the son ceased to be. But if the father-son relation is a mind-independent connection between the two relata, a real tie existing between them in the world outside our minds, perhaps a complex that includes the relata as essential parts, then it becomes easy to see how and why the destruction of one of the relata results in the destruction of the relation itself.

Further evidence for Locke's non-conceptual realism about relations can be found elsewhere in the Essay. In Book II, Chapter 28, Locke distinguishes among four kinds of relations: proportional, natural, instituted (or voluntary), and moral. Natural relations, such as 'Father and Son, Brothers, Cousin-Germans', and so on, involve comparisons in respect of 'the Circumstances of [the] origin or beginning' of the relata (E II.xxviii.2: 349). And what Locke tells us about these relations is instructive:

Mankind have fitted their Notions and Words to the use of common Life, and not to the truth and extent of Things. For 'tis certain, that in reality, the Relation is the same, betwixt the Begetter, and the Begotten, in the several Races of other Animals, as well as Men: But yet 'tis seldom said, This Bull is the Grandfather of such a Calf; or that two Pidgeons are 
Cousin-Germains. It is very convenient, that by distinct Names, these Relations should be observed, and marked out in Mankind, there being occasion, both in Laws, and other Communications one with another, to mention and take notice of Men, under these Relations: From whence also arise the Obligations of several Duties amongst Men: Whereas in Brutes, Men having very little or no cause to mind these Relations, they have not thought fit to give them distinct and peculiar Names (E II.xxviii.2: 349)

Locke's language here is more than merely suggestive. In common life, it is useful to us to mark out the fact that person $\mathrm{X}$ is the grandfather of person Y (we might be interested in the legal issue of inheritance, for instance), where it might not be useful to use to mark out the fact that this bull is the grandfather of such a calf. But Locke emphasizes that this particular relation between bull and calf is, in reality, the same as the relation between grandfather and grandchild. Where we mind or observe or take notice of a natural relation, we use a word to name it, i.e., to talk about it. So it isn't that natural relations come to be as acts of mind that do not exist until such acts are performed. Locke's comments here make no sense unless natural relations exist in the world, independently of our minds, regardless of what we bother to notice or compare. This is strong evidence indeed that nonconceptualist realism about natural relations is something that Locke almost unthinkingly takes for granted. ${ }^{15}$

In another place, Locke emphasizes the immutability of certain relations between ideas grounded in their very nature:

${ }^{15}$ Notice that, in general, there is no particular reason to argue for what one takes for granted. This might explain why Locke does not find it necessary to articulate and defend an explicit ontology of relations in the Essay. The ontology, such as it is, is presupposed.

Note that Locke's point about relations at E II.xxviii. 2 is echoed in a later section on names of mixed modes: 'Thus the Mind in mixed Modes arbitrarily unites into complex Ideas, such as it finds convenient; whilst others that have altogether as much union in Nature, are left loose, and never combined into one Idea, because they have no need of one name' (E III.v.6: 431). For example, if we 'take notice' of how the beginning of a wound is made, we will call the cause of the wound a 'stabbing', leaving out the shape of the relevant weapon. But there is a mind-independent fact of the matter about that shape, even before we choose to name it, just as there is a mind-independent fact about how bull and calf are related before we choose to mind it. 
In some of our Ideas there are certain Relations, Habitudes, and Connexions, so visibly included in the Nature of the Ideas themselves, that we cannot conceive them separable from them, by any Power whatsoever. And in these only, we are capable of certain and universal Knowledge. Thus the Idea of a right-lined Triangle necessarily carries with it an equality of its Angles to two right ones. Nor can we conceive this Relation, this connexion of these two Ideas, to be possibly mutable, or to depend on any arbitrary Power, which of choice made it thus, or could make it otherwise (E IV.iii.29: 559)

There is a necessary relation, says Locke, between the idea of a triangle and the idea of its angles adding up to two right ones. We cannot conceive how this relation could be changed or cease, depending on someone's power or choice, because it is included in the very nature of the two related ideas. If those ideas are in your mind, then no mental act of mine or yours can change the necessary relation between them. But if the relation between those ideas necessarily exists no matter what anyone else thinks, then, not only is the relation real (as opposed to chimerical), it cannot be dependent for its existence on a mental act. For if it were a mental act performed by $\mathrm{X}$, then it would cease to exist merely by $\mathrm{X}$ choosing not to perform it. ${ }^{16}$

Elsewhere, Locke emphasizes that we have trouble perceiving all the relations between ideas that there actually are. This is because many of these relations can't be immediately perceived, and it is only with some difficulty, as a result of significant effort in the shape of a proof, that they could be (mediately) perceived:

[W]e cannot have an intuitive Knowledge, that shall extend it self to all our Ideas, and all that we would know about them; because we cannot examine and perceive all the Relations they have one to another by juxtaposition, or an immediate comparison one with another...[And] therefore there is need of...Demonstration, or rational Knowledge (E IV.iii.3: 539)

${ }^{16}$ Of course, when the relata of a relation are themselves ideas, the relation must cease to exist whenever those ideas cease to exist, assuming that relations depend for their existence on the existence of their relata. But the necessity of a relation entails that it cannot itself be a mental act, contrary to the conceptualist interpretation. 
If relations were ideas, they wouldn't exist if we did not perceive them; and if they were mental acts, they wouldn't exist if we did not perform them. But what Locke tells us about relations between ideas in particular is that some of them can't be perceived immediately, even though they are there. In order to perceive them, effort in the shape of a demonstration is required; and, should the effort not be forthcoming, the relations won't be mediately perceived either, even though they haven't ceased to be. Locke's epistemic point here is straightforward: there are relations between ideas that are not, and may never be, perceived by anyone, whether immediately or mediately. This, again, suggests that relations exist independently of being perceived or performed, and hence that Locke takes non-conceptualist realism about relations between ideas for granted.

Locke beats a similar drum when he emphasizes the fact that relations between abstract ideas in particular are there to be discovered:

We must therefore, if we will proceed, as Reason advises, adapt our methods of Enquiry to the nature of the Ideas we examine, and the Truth we search after. General and certain Truths, are only founded in the Habitudes and Relations of abstract Ideas. A sagacious and methodical application of our Thoughts, for the finding out these Relations, is the only way to discover all, that can be put, with Truth and Certainty concerning them, into general Propositions (E IV.xii.7: 643)

Locke tells us here that a method is required to discover relations between abstract ideas. This makes sense on the supposition that these relations exist independently of the discoverer's mind, waiting to be discovered. But it does not make sense on the supposition that relations are ideas or mental acts, things that are perceived and known as soon as they arise in, or are performed by, the mind. Nor, of course, does it make sense on the supposition that relations between ideas do not exist: if they do not exist, then there is nothing there to be discovered. ${ }^{17}$

${ }^{17}$ It is not for nothing that Locke goes on to include within the proper compass of physics, one of the three branches of science, "[t]he Nature of Things, as they are in themselves, their Relations, and their manner of Operation' (E IV.xxi.1: 720) 


\section{\$6. Conclusion}

If relations are features of the world that do not depend for their existence on mental acts, what exactly are they? There is, as far as I know, nothing in Locke's corpus to suggest that he has a particular ontological theory of the nature of relations. But the metaphysical picture that fits most naturally with the things he says about relations is this. Locke's world is populated by substances, modes, and relations. Locke is a nominalist, in the sense that there are no intrinsically general things (no universals): 'General and Universal, belong not to the real existence of Things; but are the Inventions and Creatures of the Understanding, made by it for its own use, and concern only Signs, whether Words, or Ideas' (E III.iii.11: 414). Instead, 'all things that exist are only particulars' (E III.iii.6: 410). Thus, there are only particular substances, particular modes, and particular relations in Locke's universe.

Substances, as we have seen, are 'distinct particular things subsisting by themselves' (E II.xii.6: 165). Modes are 'Dependences on, or Affections of Substances' (E II.xii.4: 165). So substances are particular things that do not depend for their existence on the existence of anything else. Each mode, by contrast, is a particular thing that depends for its existence on the existence of a particular substance. For example, each human being is a substance, and the particular shape or height of that human being is a mode of that substance. Even mixed modes, such as lies and instances of theft, are committed by particular substances, and would not exist if the relevant perpetrators did not exist.

Like modes but unlike substances, relations are dependences on other entities. ${ }^{18}$ But unlike modes, relations are not affections:

${ }^{18}$ I assume here that the relata of a relation need not be substances: they can be modes or relations. For example, we may presume that Locke would hold that the relation of being worse than obtains between the mode of parricide and the mode of theft, and that the relation of 'containing more relata than' obtains between the relation of betweenness (as in 'A's being between B and C') and the relation of being larger than (as in 'A's being larger than B'). (Thanks to Ken Winkler for bringing this issue to my attention.) 
they are, instead, ordered wholes composed of their relata and a ground of comparison. ${ }^{19}$ As Locke might be putting the point in Draft A of the Essay: 'In all relation then though there be but one word commonly used to expresse it there is included the two things which are compard one with an other \& the occasion or ground of that comparison'. The relation of being-larger-than that obtains between my house and my mouse consists in an ordered triplet, <my house, size, my mouse>. (The triplet must be ordered, because the relation of being-larger-than does not obtain between my mouse and my house.) This hypothesis explains why relations exist independently of mental acts, and why a relation ceases to be when either of its relata is removed or ceases to be. ${ }^{20}$ According to this picture, Locke is a non-conceptualist realist about relations, just as he is a non-conceptualist realist about modes and substances. ${ }^{21}$

\section{University of California, San Diego}

${ }^{19}$ For more discussion of structured wholes, see Rickless 2014, 46-48.

${ }^{20}$ On the side of the mind, Locke's view is that ideas of relation, i.e., ideas that represent relations that exist in the world as dependences of other entities, are formed by comparing ideas of those entities along particular dimensions, and then combining these ideas with the idea of the relevant dimension. But ideas of relation are not formed with the intent of representing relations per se, but with the intent of representing themselves. This is why ideas of relation are real and adequate, in the technical senses of these words that Locke introduces in E II.xxx and E II.xxxi.

${ }^{21}$ I am grateful to the anonymous referees and Timothy Stanton at Locke Studies for their comments on, and assistance with, this paper. I started thinking seriously about the issues discussed in this paper after attending a stimulating talk by Walter Ott at a meeting of the Central Division of the American Philosophical Association in March 2014. I presented an ancestor of the paper at a Locke Workshop at Yale University in October 2014. Many thanks to the organizer, Ken Winkler, to the commentator on my presentation, Julia Borcherding, and to the workshop participants (including Martha Bolton, Matthew Leisinger, Alex Silverman, Matthew Stuart, Jonathan Vertanen) for their probing and constructive questions. And I am particularly indebted to Patrick Connolly for helpful correspondence. 


\section{REFERENCES}

Bennett, Jonathan. 1971. Locke, Berkeley, Hume: Central Themes. Oxford. Bolton, Martha Brandt. 2007. 'The Taxonomy of Ideas in Locke's Essay'. In The Cambridge Companion to Locke's "Essay Concerning Human Understanding”, ed. Lex Newman, 67-100. Cambridge.

Gibson, James. 1917. Locke's Theory of Knowledge and Its Historical Relations. Cambridge.

Green, Thomas Hill. 1885. The Works of Thomas Hill Green, vol. 1, ed. R. L. Nettleship. London.

Kripke, Saul. 2013. Reference and Existence. Oxford.

Langton, Rae. 2000. 'Locke's Relations and God's Good Pleasure', Proceedings of the Aristotelian Society 100: 75-91.

Locke, John. 1975. An Essay Concerning Human Understanding, ed. Peter H. Nidditch. Oxford.

Odegard, Douglas. 1969. 'Locke and the Unreality of Relations', Theoria 35: $147-52$.

Ott, Walter. 2009. Causation and Laws of Nature in Early Modern Philosophy. Oxford.

Ott, Walter. Forthcoming. "“Archetypes Without Patterns": Locke on Relations and Mixed Modes', Archiv für Geschichte der Philosophie.

Pasnau, Robert. 2011. Metaphysical Themes 1274-1671. Oxford.

Perry, David. 1967. 'Locke on Mixed Modes, Relations and Knowledge', Journal of the History of Philosophy 5: 219-35.

Rickless, Samuel C. 2014. Locke. Oxford.

Stuart, Matthew. 2013. Locke's Metaphysics. Oxford. 